\title{
Primary studies on the effect of coal bio-gasification in situ in the Qinshui basin
}

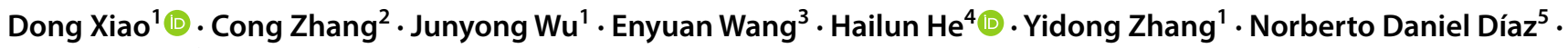 \\ Liuping Deng ${ }^{2} \cdot$ Meng Wang ${ }^{4}$
}

Received: 15 October 2021 / Accepted: 22 November 2021 / Published online: 29 November 2021

(c) The Author(s) 2021

\begin{abstract}
Coal bio-gasification is one in situ coal gasification technology that utilizes the digestion of organic components in coal by methanogenic bacteria. It is not only an effective technology to enhance the recoverable reserves of coalbed methane, but also an important technical method to promote clean coal utilization. Relevant laboratory researches have confirmed the technical feasibility of anthracite bio-gasification. However, in the complex environment of coal bed, whether in situ gas can be yield with methanogenic bacteria needs to be verified by in situ experiments. In this study, a vertical well and a horizontal well were used in Qinshui basin to perform field experiments to confirm the technical industrial feasibility. The concentration of $\mathrm{Cl}^{-}$ion and number changes of Methanogen spp. were used to trace nutrition diffusion. Gas production changes and coalbed biome evolution were used to analyze technical implementation results. The trace data and biome evolution identified that: (1) The development of Methanoculleus spp. has a significant positive correlation with culture medium diffusion; (2) the structure of coalbed microbial community was significantly changed with the injection of nutrition, and the newly constructed methanogenic community was more suitable for fermentation of coal; and (3) the evolution of dominant microflora has further enhanced bio-gasification of coal. Gas production data showed that the gasification of coal lasted 635 and 799 days and yielded $74,817 \mathrm{~m}^{3}$ and $251,754 \mathrm{~m}^{3}$ coalbed methane in Z-159 and Z-7H wells, respectively. One nutrition injection in coalbed achieved an average of 717 days of continuous gas production in experimental wells. Results confirmed that coalbed methane enhancement with bio-gasification of coal is a potential technology to achieve the productivity improvement of coalbed methane wells. And the findings of this study can help to further understand the mechanism of in situ coal bio-gasification and provide theoretical support for the development of biomining of coal.
\end{abstract}

Keywords Coal bed methane $\cdot$ Bio-gasification $\cdot$ Bioenergy $\cdot$ Clean coal $\cdot$ Methanogen spp $\cdot$ Biome evolution

\section{Abbreviations}

CBM Coal bed methane

TCD Thermal conductivity detector

Dong Xiao and Enyuan Wang have contributed equally to this work and should be considered co-first authors.

Dong Xiao

xd@cumt.edu.cn

Hailun He

helenhe@scu.edu.cn

Extended author information available on the last page of the article

\section{Introduction}

Coal bed methane (CBM) is a type of associated gas resulting from coal production. The main component of this gas is $\mathrm{CH}_{4}$. $\mathrm{CBM}$ is a valuable energy resource; meanwhile, it is a dangerous source for mining(Szlązak et al. 2020). CBM extraction is of great significance both in terms of improving the clean utilization of coal and improving mining safety. (Kretschmann 2020). Related researches such as increasing the reserves of coalbed methane(Wang et al. 2014), improving the coal porosity(Xu et al. 2017) have become the research focus of coal fluidized mining. Therefore, research involving coal gasification methods, gas drainage mechanisms, and applications, which serves to improve gas well productivity, has gradually deepened (Zhang et al. 2020; Guo et al. 2021; Yan et al. 2021). Coal bio-gasification is a key technology, and related research started in the 
USA (Malik et al. 2020). At present, laboratory research has clarified the mechanism of coal microbial metabolism, explored the microbial community structure and cooperation methods, and established a variety of culture methods. The research and effect evaluation of in situ bio-gasification technology implementation is at the initial stage in China. The field experiment of coal microbial gasification lays one theoretical foundation for technological industrialization. In this research, the concentration of $\mathrm{Cl}^{-}$ion and number changes of target bacteria were used to trace nutrition diffusion. Gas production changes and coalbed biome evolution were used to analyze technical implementation results (Fig. 1). Comprehensive data differences between experimental wells and blank wells realized the evaluation of coal microbial in situ gasification effect.

Based on previous studies, the Qinshui Basin was selected for this study. This basin is located in the southern region of the Shanxi province, has an abundance of CBM and constitutes one of the most important CBM reservoirs and gas development regions in China (Fig. 2). The CBM reserves are estimated at 3.95 trillion $\mathrm{m}^{3}$ within this $27,137 \mathrm{Km}^{2}$ area (Zhang et al. 2018). As defined by the Chinese petroleum and natural gas reserves standard, this basin represents a massive gas field. The geologic structure of the Qinshui basin is comprised of the compound syncline, which warps the seams of the southern and northern basins and supplies the fundamental symmetry-bearing portion of the eastern and western regions.

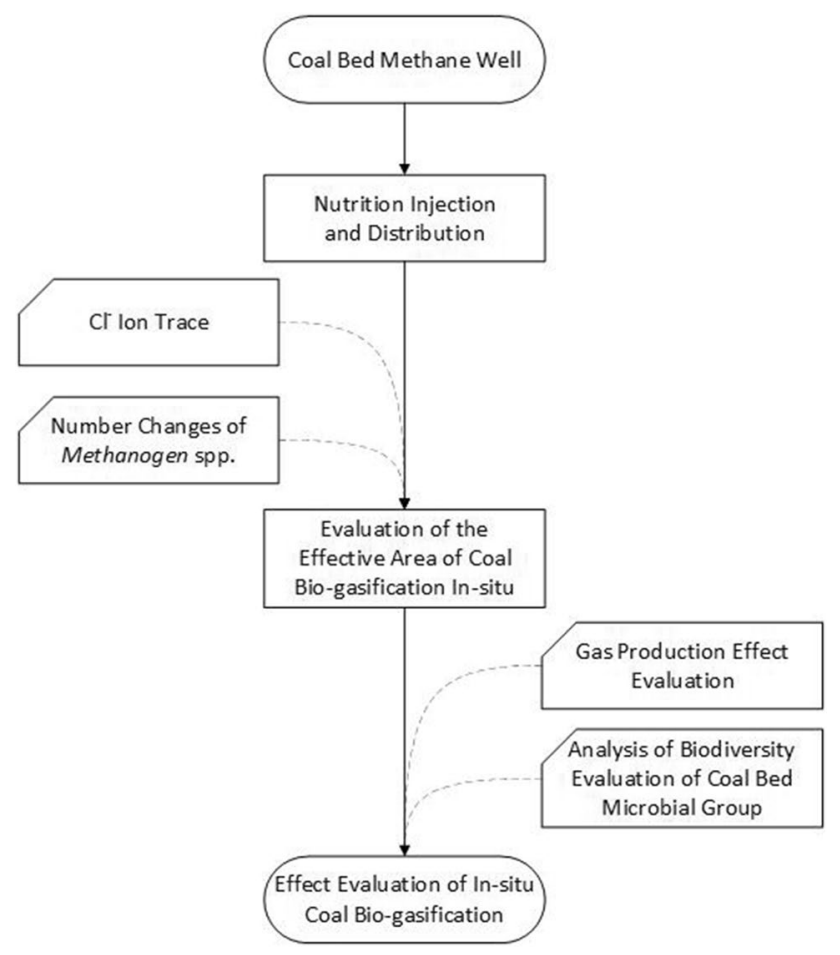

Fig.1 The technical route of in situ coal bio-gasification

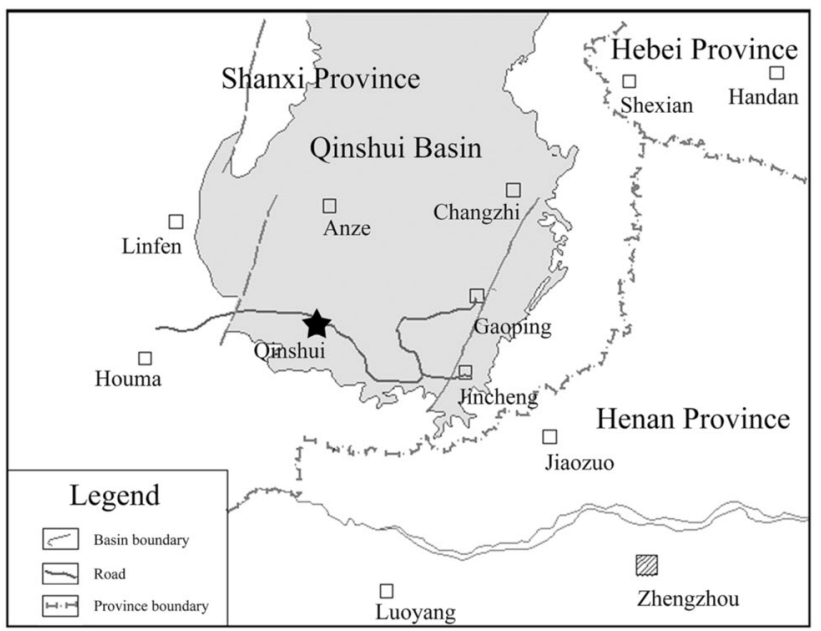

Fig. 2 The Qinshui Basin geographical location map. The Qinshui Basin is located in the southern part of Shanxi Province. Neighboring provinces of Herbei and Henan. Anze, Changzhi, Qinshui, Gaoping, and Jincheng are the main coal bed gas development areas. The test location was in Qinshui, where marked with a pentagram symbol in the figure

The geologic structure in the middle of this basin is flat and contains few faults. The FM $3^{\#}$, FM $9^{\#}$ and FM $15^{\#}$ coal beds are the main gas-bearing layers with good permeability conditions (Liang 2015).

Methane productivity of some CBM wells is quite low and even did not produce gas in part wells, which like Z-7H, Z-159, and Z-163 wells in the experiment. Gas foam fracturing has been used in these wells to expand crack and improve coal permeability(Ji et al. 2018). However, the effect was not satisfying. In this case, the CBM development cost was prohibitive(Wang et al. 2014). In previous research, methanogenic bacteria, which include hydrolytic fermentation bacteria, fermenting bacteria, and Methanogen spp., etc., had been found in FM $3^{\#}$, FM $9^{\#}$ coal bed in Qinshui basin, and the microbe culture method had been studied also(Xiao et al. 2015). If the coal bio-gasification technology can be applied on-site, it would prove a potential technology to improve gas wells production efficiency and control the cost of CBM development.

The step of the work: This research goes through importants steps such as the materials and methods describing, the effective influence area of the nutrient analyzing, the gas production effect and the diversity change of the coalbed microbial community by the technology implementation comparative analyzing, and finally, the experimental summary and conclusions are exposed. 


\section{Materials and methods}

\section{Experiment wells and control wells survey}

This experiment was carried out in a horizontal multiple branching well and a vertical well. The horizontal well identified as Z-7H (GPS coordinates: $38.716117,106.475351$ ) and Z-159(GPS coordinates: 35.710277, 112.472500). Z-163, Z-167wells, which were located beside the test wells, were selected as control wells.

Total drill footage of Z-7H well was $5472 \mathrm{~m}$, the pure drilling footage in coal was $4405 \mathrm{~m}$, and the well control area consisted of $0.371 \mathrm{Km}^{2}$. The connection point depth was $797.5 \mathrm{~m}$, and the deflection point depth was $508 \mathrm{~m}$. The well diameter was 6 inches. The Z-7H well has two main well bores and nine branches. The gently sloping coal seam provides for a favorable geographical condition (Fig. 3). The well was completed on October 15, 2012. The desorption pressure gradually increased and achieved a value of $2.5 \mathrm{MPa}$ and began to produce gas on February 23, 2013. However, Z-7H stopped gas production after $644 \mathrm{~m}^{3}$ of gas was produced from February to March. The average gas production over the production period was only $64.37 \mathrm{~m}^{3} /$ day from its initial commissioning until the end of 2014.

Z-159, Z-163, Z-167 wells were open vertical boreholes, located adjacent to the horizontal pinnate branch well of Z-7H (Fig. 3) and had similar geological conditions to that of Z-7H. The wells diameter was 6 inches, was completed on September to December 2012, and drilling depth of each borehole was $572.5 \mathrm{~m}, 591.9 \mathrm{~m}, 607.9 \mathrm{~m}$, respectively. No gas was obtained in Z-159 and Z-163 wells before the experiment was performed. Many nitrogen foam fracturing and flushing operations were carried out in $\mathrm{Z}-7 \mathrm{H}, \mathrm{Z}-159$ and Z-163 wells to expand crack and improve coal permeability, but failed. Well Z-167 had gas productivity of $460 \mathrm{~m}^{3} /$ day on average before the experiment was performed.

\section{Condition of the FM $3^{\#}$ coal seam}

FM $3^{\#}$ coal in Qinshui is anthracite with a value of $\mathrm{R}_{\mathrm{o} \text {,max }}>3.0$, and the thickness of the seam is $2.0-7.3 \mathrm{~m}$ (average $3.8 \mathrm{~m}$ ). This coal seam is formed of semibright coal and glance coal, and a small amount of semidull coal. The porosity of FM $3^{\#}$ coal averages $4.88-6.14 \%$. The main structure in this coal seam is formed by an initial fissure; fissure non-development. The fissure number is $6-11$ per $5.0 \mathrm{~cm}$, length is $0.5-10.0 \mathrm{~cm}$, and width is $2.0-120.0 \mu \mathrm{m}$. The connectivity of these fissures is low and is influenced by a calcite film in the coal. The average permeability of FM $3^{\#}$ coal is $0.02 \mathrm{mD}$, which was tested using the injection-falloff method in this zone. The reservoir pressure for coal bed gas is 5.0-7.0 MPa, the fluid pressure gradient is $0.07-0.09 \mathrm{MPa} / \mathrm{m}$, and the desorption pressure is 2.0-2.5 MPa. Blockages form easily in this coal seam with a non-development fissure.

\section{Medium preparation and injection}

A standard medium was used to provide acclimation and culture the Methanogen spp. in the coal bed. The final concentrations of the compounds $\left(\mathrm{kg} / \mathrm{m}^{3}\right)$ were: yeast extract, $0.50 ; \mathrm{NaHCO}_{3}, 0.05 ; \mathrm{NH}_{4} \mathrm{Cl}, 2.30 ; \mathrm{KH}_{2} \mathrm{PO}_{4}, 1.30 ; \mathrm{K}_{2} \mathrm{HPO}_{4}$, $0.70 ; \mathrm{NaCl}, 0.05 ; \mathrm{MgSO}_{4} \bullet 7 \mathrm{H}_{2} \mathrm{O}, 0.20 ; \mathrm{CaCl}_{2} \bullet 2 \mathrm{H}_{2} \mathrm{O}, 0.05$. The final $\mathrm{pH}$ was 6.80 , and the $\mathrm{Cl}^{-}$ion concentration was $44.59 \mathrm{mmol} / \mathrm{L}$ (Xiao et al. 2015).

$100 \mathrm{~m}^{3}$ medium was prepared for Z-7H well, and $30 \mathrm{~m}^{3}$ medium was prepared for Z-159 well. The medium was prepared with a $50 \mathrm{~m}^{3}$ tank car, and injection was performed with a fracturing truck (4150 8X8, Benz, Germany). The injection pressure was adjusted and maintained at less than 4.00 MPa. The Z-159 well and Z-7H well were sealed on March 11 and 26, 2015. And the wellhead pressure was monitored no less than 2 months.
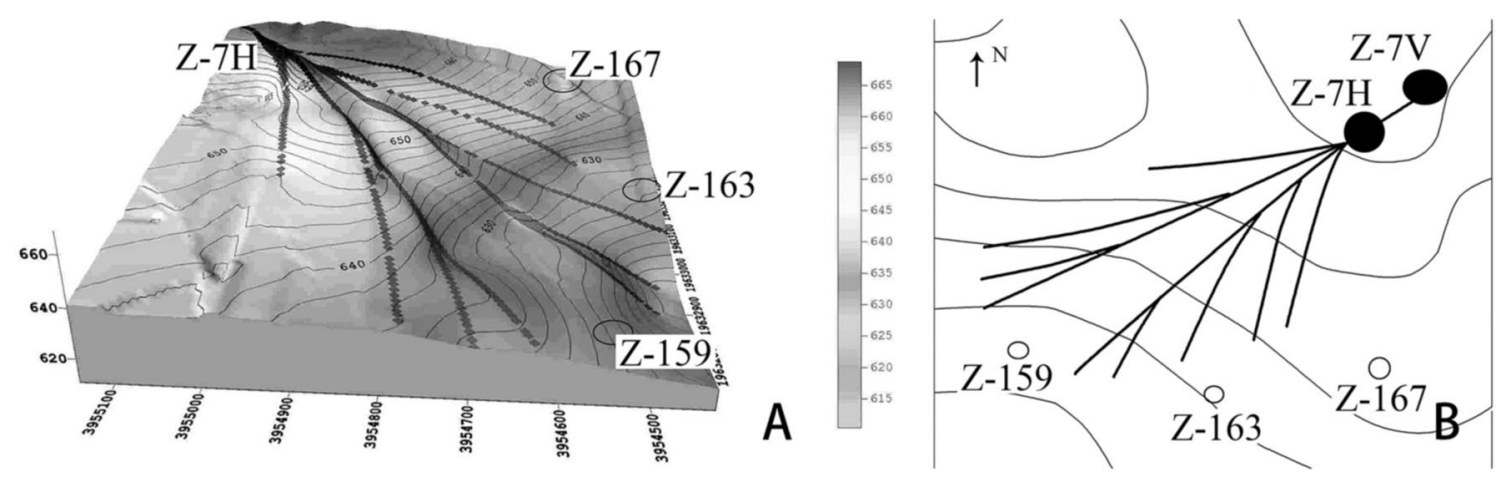

Fig. 3 Well Z-7H trajectory stereogram and contour map. Relative geographic locations next to Z-7H well. Wells Z-159, Z-163, and Z-167 are located in the south of $\mathrm{Z}-7 \mathrm{H}$ well 


\section{Medium diffusion monitors}

Medium diffusion in coal seam was monitored by $\mathrm{Cl}^{-}$concentration changes within the underground water (Xiao et al. 2015). Concentrations of $\mathrm{Cl}^{-}$were identified using an ICS-1100 ion chromatography system (Thermo Scientific Dionex, Bannockburn, the USA). The underground water sample was collected in wells Z-159, Z-163, Z-167, and $\mathrm{Z}-7 \mathrm{H}$ and used aseptic, anaerobic $50 \mathrm{ml}$ tubes. High-speed multifunction centrifugation (J2-MC, Beckman Instruments, Fullerton, USA) and 0.22um filter membrane were utilized to separate the suspended particles and microbes in underground water samples. Purified samples were stored at $-80{ }^{\circ} \mathrm{C}$ in a refrigerator (DW-86L728J, Haier, Qingdao, China).

\section{Microbial observation}

Observations of microbe formation, fluorescence detection, and microbial counting were performed using an Olympus BX41 (Olympus, Tokyo, Japan) fluorescence microscope at $400 \times$ and $1000 \times$ magnification with a blood cell counting plate. The F420 fluorescence method was used to test for the presence of methanogenic bacteria (Barnhart et al. 2013).

\section{CBM wells productivity monitor}

CBM production; methane, carbon dioxide, and nitrogen concentrations were the parameters used to analyze gas productivity and identify the effects of biological coal gasification. Gas production rates in each well were monitored using a gas roots flow meter (model: FLLQ, Fuma, Wenzhou, China). Measurement accuracy of the FLLQ gas roots flow meter was class 1.0, and flow range of this meter was $0.6-400 \mathrm{~m}^{3} / \mathrm{h}$.

The concentration of $\mathrm{CH}_{4}$ and $\mathrm{CO}_{2}$ was analyzed using Agilent 7890A gas chromatograph (Agilent, Tokyo, Japan). The nitrogen (carrier gas) flow rate was fixed at $1 \mathrm{ml} / \mathrm{min}$. The injection port was maintained at $150{ }^{\circ} \mathrm{C}$, the oven temperature was $25^{\circ} \mathrm{C}$, and the TCD was operated at $200{ }^{\circ} \mathrm{C}$. Retention time for methane was $3.76 \mathrm{~min}$ and $5.0 \mathrm{~min}$ for $\mathrm{CO}_{2}$. Calibration standards consisting of $40 \%$ methane, $20 \% \mathrm{CO}_{2}, 10 \%$ hydrogen and $30 \%$ nitrogen were injected at atmospheric pressure to provide the calibration plot.

\section{DNA extraction and PCR}

$100 \mathrm{~mL}$ of underground water in the $\mathrm{Z}-7 \mathrm{H}$ well was collected at the initial and termination stages of this experiment. Bacteria was concentrated to $1 \mathrm{~mL}$ by centrifugation (J2-MC, Beckman Instruments, Fullerton, the USA) and stored in cryovials at $-80{ }^{\circ} \mathrm{C}$ (refrigerator type: DW86L728J, Haier, Qingdao, China) until DNA was extracted.
The centrifugal force was set to $13,000 \times \mathrm{g}$ and centrifuged for $10 \mathrm{~min}$. Total genomic DNA was extracted from $1 \mathrm{~mL}$ concentrated underground water samples using E.A.N.A. Soil DNA Kit (OMEGA, Georgia, GA, the USA) following the manufacturer's instructions.

The V4 region of 16S rRNA gene was amplified with polymerase chain reaction (PCR) using primers $515 \mathrm{~F}$ (5'- GTG CCA GCM GCC GCG GTAA-3') and 806R (5'- GGA CTA CHV GGG TWT CTA AT-3') (Green et al. 2008). The primer pair was reported to generate an optimal community clustering with the sequence length in the V4 region (Schloss et al. 2016). Each $20 \mu \mathrm{L}$ PCR reaction was composed of $2 \mathrm{ng}$ of template DNA, $0.2 \mu \mathrm{M}$ primers, $0.2 \mathrm{mM}$ dNTP, $2 \mu \mathrm{L} 10 \times$ Pfu Buffer with $\mathrm{MgSO}_{4}$ (Applied Thermo, Califonia, CA, the USA), with $\mathrm{H}_{2} \mathrm{O}$ up to $20 \mu \mathrm{L}$. The DNA amplification was performed under the following cycling conditions: 1 cycle of $2 \mathrm{~min}$ at $95^{\circ} \mathrm{C}$, followed by 30 cycles with $30 \mathrm{~s}$ at $95{ }^{\circ} \mathrm{C}, 30 \mathrm{~s}$ at $55^{\circ} \mathrm{C}$ and $1 \mathrm{~min}$ at $72{ }^{\circ} \mathrm{C}$, then a final extension period of $5 \mathrm{~min}$ at $72{ }^{\circ} \mathrm{C}$. Before sequencing on the Illumina Miseq sequencing platform, we would amplify the V4 region by adding sample-specific 10-base barcodes and universal sequencing tags by sample-specific PCR protocol. The PCR procedure was as following: 1 cycle of $95^{\circ} \mathrm{C}$ at $2 \mathrm{~min}, 15$ cycles of $95^{\circ} \mathrm{C}$ at $15 \mathrm{~s}, 60^{\circ} \mathrm{C}$ at $30 \mathrm{~s}$, $68{ }^{\circ} \mathrm{C}$ at $1 \mathrm{~min}$, the final step was 1 cycle of $68^{\circ} \mathrm{C}$ at $3 \mathrm{~min}$. Equal volume of each barcoded product was pooled into amplicon libraries and purified using Agencourt AMPure XP system (Beckman Coulter, CA, the USA) then examined on Agilent Bioanalyzer 2100 for product size distribution. The purified libraries were quantified with Qubit ${ }^{\circledR}$ dsDNA HS Assay Kit (Life Technologies, CA, the USA) and used for sequencing.

\section{Sequencing and data analysis}

16S rRNA gene libraries were sequenced using an Illumina MiSeq (San Diego, CA, the USA) platform, and the sequencing data were base-called and demultiplexed using MiSeq Reporter v.1.8.1 (Illumina, SanDiego, CA, the USA) with default parameters. The adapter sequences and low quality reads were trimmed away from the raw reads with Trimmomatic v.0.32 (Xie et al. 2018). Then, the clean reads were analyzed using the Uparse (Allali et al. 2017) and Mothur pipeline (Fosso et al. 2015) to generate operational taxonomic units (OTUs). The OTUs were picked out at $97 \%$ similarity (Neves et al. 2017). The resulting representative sequence set was aligned against the core sequence database of the SILVA 123 release with the Mothur script (www. mothur.org/) and given a taxonomic classification using RDP at the $80 \%$ confidence level (Wang et al. 2007). The richness estimators (ACE and Chao1) and diversity indices (Shannon and Simpson) were calculated using the Mothur program. OTUs' comparisons were performed using the Venn 
diagram package. Neighbor-joining phylogenetic tree was used to investigate the similarity of species abundance using the unweighted pair group method with arithmetic mean (UPGMA) clustering method (McNeil and Alibali 2004).

\section{Results and discussion}

\section{Medium diffusion in coal bed}

The key factor needed to enhance the biodegradation of coal is nutrient distribution in coal. Z-159 and Z-7H were the medium injection wells in the experiments. And the medium was injected on March 10 and 25, 2015, respectively. Meanwhile, the Z-163 and Z-167 wells were the contrast wells. The coal bed water samples were collected before the medium was injected, and on February 7, 2016, after the Z-159 and Z-7H wells resumed gas production. The change in $\mathrm{Cl}^{-}$ion concentration was served as an indicator to assess whether the medium had diffused in surrounding wells field.

Chloride, in the form of the $\mathrm{Cl}^{-}$ion, constitutes one of the major inorganic anions in coalbed water. It originates from the dissociation of salts, such as sodium chloride or calcium chloride, in water(Grzegorzek et al. 2020). These salts, and their resulting chloride ions, come from coal seam minerals. Medium diffusion in coal changed the $\mathrm{Cl}^{-}$ion concentration in the coal seam fissure water, and as a result of anthropogenic impacts(Chen et al. 2017). The concentration of $\mathrm{Cl}^{-}$in the coal seam fissure water of wells Z-7H and Z-159 was altered following nutrition medium injection, showing significant variations in $\mathrm{Cl}^{-}$concentrations due to the effects of nutrition distribution. $\mathrm{Cl}^{-}$concentrations would increase in other wells if there was nutrition seepage flow into the control area of neighboring wells.

Baseline $\mathrm{Cl}^{-}$concentrations for the Z-159, Z-163, $\mathrm{Z}-167$, and $\mathrm{Z}-7 \mathrm{H}$ wells were considered to be stable at $100 \sim 110 \mathrm{mg} / \mathrm{L}$. This value increased two to three times in 70 days after the experiments were performed for the Z-159 and $\mathrm{Z}-7 \mathrm{H}$ wells. In contrast, the $\mathrm{Cl}^{-}$concentration within the Z-163 and Z-167 wells was maintained at about the same level over the experimental period (shown in Table 1). These findings confirmed that the distribution of the culture medium and the coal bio-gasification were active in the Z-159 and Z-7H wells and did not seepage to the Z-163 and Z-167 wells.

\section{Changes in the number of Methanogen spp.}

The bio-gasification of coal is performed through the collaboration of different microorganisms(Hoang et al. 2021; Mei et al. 2021). They include hydrolytic fermentation bacteria, fermenting bacteria, and Methanogen spp., etc. (Green et al. 2008). And these bacteria had been found in FM $3^{\#}$, FM $9^{\#}$ coal bed in Qinshui basin (Xiao et al. 2013, 2017). As the terminal bacteria of coal bio-gasification process, Methanogen spp. can indicate the development of methanogenic consortia for coal biodegradation in coal bed (Barnhart et al. 2013). The number of Methanogen spp. in the sample could be observed by fluorescence microscopy, because Methanogen sp. has a fluorescent effect in $420 \mathrm{~nm}$ light(Strąpoć et al. 2008; Xiao et al. 2013). On this condition, it has a positive correction between bio-gasification of coal with the number of Methanogen spp. Quantitative analyses of Methanogen spp. were performed before the medium was injected, and on February 7, 2016, when the Z-159 and Z-7H wells resumed gas production. Initial levels of Methanogen spp. were lower than $1.25 \times 10^{5}$ per $\mathrm{ml}$ on average in the experimental and contrast wells. The Methanogen spp. numbers increased from less than $1.25 \times 10^{5}$ to $5.60 \times 10^{7}$ and $7.60 \times 10^{7}$ per $\mathrm{ml}$ in the Z-159 and Z-7H wells with the medium diffusing in the coal bed (shown in Table 1). Meanwhile, the number was stable at the original level in the Z-163 and Z-167 wells. These findings confirmed that the methanogenic consortia developed with intervention and created biological conditions for bio-gasification of coal.

\section{Effect analysis of bio-gasification of coal}

Bio-gasification of coal was performed through the biofermentation of organic compounds in the coal. $100 \mathrm{~m}^{3}$ and
Table $1 \mathrm{Cl}^{-}$concentration, Methanogen spp. number, and gas concentrations changes, before and during the experiments

\begin{tabular}{|c|c|c|c|c|c|c|}
\hline & \multirow[t]{2}{*}{ Well } & \multirow{2}{*}{$\begin{array}{l}\mathrm{Cl}^{-} \text {concentra- } \\
\text { tion } \mathrm{mmol} / \mathrm{L}\end{array}$} & \multirow{2}{*}{$\begin{array}{l}\text { Methanogen spp. } \\
\text { number Per ml }\end{array}$} & \multicolumn{3}{|c|}{ Gas concentrations $\% \mathrm{Vol}$} \\
\hline & & & & $\overline{\mathrm{CH}_{4}}$ & $\mathrm{CO}_{2}$ & $\mathrm{~N}_{2}$ \\
\hline \multirow[t]{4}{*}{ Before the experiment } & Z-159 & 1.92 & $<1.25 \times 10^{5}$ & $97.21 \%$ & $2.65 \%$ & $0.14 \%$ \\
\hline & Z-163 & 1.98 & $<1.25 \times 10^{5}$ & $98.02 \%$ & $1.95 \%$ & $0.03 \%$ \\
\hline & Z-167 & 1.96 & $<1.25 \times 10^{5}$ & $97.52 \%$ & $2.36 \%$ & $0.12 \%$ \\
\hline & $\mathrm{Z}-7 \mathrm{H}$ & 2.03 & $<1.25 \times 10^{5}$ & $97.82 \%$ & $2.11 \%$ & $0.07 \%$ \\
\hline \multirow[t]{4}{*}{ After the experiment } & Z-159 & 5.40 & $5.60 \times 10^{7}$ & $87.00 \%$ & $12.88 \%$ & $0.12 \%$ \\
\hline & Z-163 & 2.01 & $<1.25 \times 10^{5}$ & $97.45 \%$ & $2.44 \%$ & $0.11 \%$ \\
\hline & Z-167 & 2.04 & $<1.25 \times 10^{5}$ & $97.82 \%$ & $2.03 \%$ & $0.14 \%$ \\
\hline & $\mathrm{Z}-7 \mathrm{H}$ & 4.01 & $7.60 \times 10^{7}$ & $79.95 \%$ & $19.97 \%$ & $0.08 \%$ \\
\hline
\end{tabular}


$30 \mathrm{~m}^{3}$ of medium were injected into the $\mathrm{Z}-7 \mathrm{H}$ and $\mathrm{Z}-159$ wells and were used to provide main nutrients for microbial growth in the coal. The Z-159 well resumed gas production on May 23, 2015, and terminated on February 16, 2017. And the Z-7H wells resumed gas production on June 7, 2015, and terminated on August 14, 2017. The gasification of coal lasted 635 and 799 days (average 717 days) and yielded $74,817 \mathrm{~m}^{3}$ and $251,754 \mathrm{~m}^{3} \mathrm{CBM}$ in Z-159 and Z-7H wells, respectively. $\mathrm{Z}-7 \mathrm{H}$ is a horizontal multiple branching well and total drill footage is $5472 \mathrm{~m}$, the amount of wellcontrolled anthracite is around 1.97 MTon. The volume of injected medium was about $100 \mathrm{~m}^{3}$. Cumulative gas production per unit was $0.128 \mathrm{~m}^{3} /$ Ton, and the gas production ratio of medium was $2.52 \mathrm{~m}^{3} / \mathrm{L}$. Meanwhile, $\mathrm{Z}-159$ is a vertical well and drill depth is $752.5 \mathrm{~m}$, the amount of wellcontrolled anthracite is around 0.38 MTon, only $19.14 \%$ of $\mathrm{Z}-7 \mathrm{H}$ control area. The volume of injected medium was 22 $\mathrm{m}^{3}$. Cumulative gas production per unit area was $0.197 \mathrm{~m}^{3} /$ Ton, and the gas production ratio of medium was $3.40 \mathrm{~m}^{3} / \mathrm{L}$. Effected by control coal volume, $\mathrm{Z}-7 \mathrm{H}$ has the highest total gas yield, the longest gas production cycle, and the gas production rate was relatively stable. However, according to the gas yield rate, Z-159 was 1.54 times higher than Z-7H. The gas production of contrast wells maintained the original characteristics during the experiment (Fig. 3). In particular, the Z-163 well maintained at non-gas productive state during gas productivity has resumed in experimental wells. Compared data above, Z-159 got higher coal bio-gasification rate. It needs to be noted that the unit conversion rate data in this research are used to compare the bio-gasification difference between experimental wells only, with the influence of coal permeability, biological metabolism rate, the data cannot represent the effective $\mathrm{FM}^{\#}{ }^{\#}$ coal bio-gasification rate.

Comprehensive multi-factor analysis was needed to verify the CBM increase in experimental wells whether was related to the microbial degradation of coal. According to on-site experimental conditions, this research was integrated the indicators of $\mathrm{CO}_{2}$ concentration, $\mathrm{Cl}$ - ion concentration, and biome diversity in underground water. Ion tracers indicate that the nutrition diffused in the Z-159 and Z-7H wells in experiments. With the effect of nutrition control, Methanogen spp. numbers increased, from lower than $1.25 \times 10^{5}$ to more than $5.60 \times 10^{7}$ per $\mathrm{ml}$, in nutrition injected wells. These data were found to have a positive correlation with the changes in gas productivity in certain wells (Fig. 4).

The $\mathrm{CO}_{2}$ content in FM 3\# coalbed is less than 3.0\%. But this factor in experimental wells increased to Z-7H: $19.97 \%$ and $Z$-159: $12.88 \%$. Increased 9.46 and 4.86 times, respectively, compared with before the experiment. The yield of $\mathrm{CO}_{2}$ in coal bio-gasification should around $30-50 \%$ in generally. The $\mathrm{CO}_{2}$ concentration in situ bio-fermentation should be much lower which infect with the coal adsorption and displacement characteristics of $\mathrm{CO}_{2}$ to $\mathrm{CH}_{4}$. The abnormal changes in CBM components of experiment wells can preliminarily proved that the increase in CBM production was related to biological activities in coal bed. Therefore, the increase in the $\mathrm{CO}_{2}$ content of the CBM could be an important indication of the bio-gasification phenomenon of the coal (indicated in Table 1). The gas components of CBM in Z-167, which without influence of medium injection, were maintained at a stable level.

\section{Analyses of changes in microbial community structure}

Different microbial populations and coal constitute a coal bed ecological community. Microbial community ecology evolution is closely related to the changes of coal bed environment factors. These factors include gas composition, nutrition, and specific surface area of coal (Xiao et al. 2017). Biodiversity testing before and after the experiment in $\mathrm{Z}-7 \mathrm{H}$ well had confirmed this evolution. Data indicated that microbial species have significant changes with medium injection in coal (Fig. 5).

There were 105 strains detected in high-throughput sequencing of the original coal bed microbial community before the experiment. High relatively abundant genus was as follows: Propionibacterium, Balneimonas, Anoxybacillus, Cupriavidus, Schlegelella, Clostridium, Clostridium, Pseudoalteromonas, Pseudoalteromonas, etc. After cultured, meanwhile, the detected strains value in high-throughput sequencing of the $\mathrm{Z}-7 \mathrm{H}$ well biome decreased to 85 . And compare the microbial community structure before and after experiment, only 11 species were the common species. And the number of common species with a relative abundance higher than $0.5 \%$ is only four, which include: Anoxybacillus_kestanbolensis, Escherichia_coli, Cupriavidus, Schlegelella. Analysis of the response of coal bed biome to environmental changes and community evolution showed that two groups of microorganisms were the most obvious. First of all was Methanoculleus spp. and Methanosarcina spp., both of them belong to the family Methanomicrobia spp. Most methanogen spp. make methane from $\mathrm{CO}_{2}$ and $\mathrm{H}_{2}$. Others utilize acetate in the acetoclastic pathway. In addition to these two pathways, species of Methanosarcina spp. can also metabolize methylated one-carbon compounds through methylotrophic methanogenesis. Such one-carbon compounds include methylamines, methanol, and methyl thiols (Galagan et al. 2002). Only Methanosarcina spp. species possess all three known pathways for methanogenesis and are capable of utilizing no less than nine methanogenic substrates, including acetate (Maeder et al. 2006). Methanoculleus spp. is different from other methanogens, it can use ethanol and some secondary alcohols as electron donors as they produce methane (Asakawa and Nagaoka 2003). And followed by Anaerolinea and some species from 


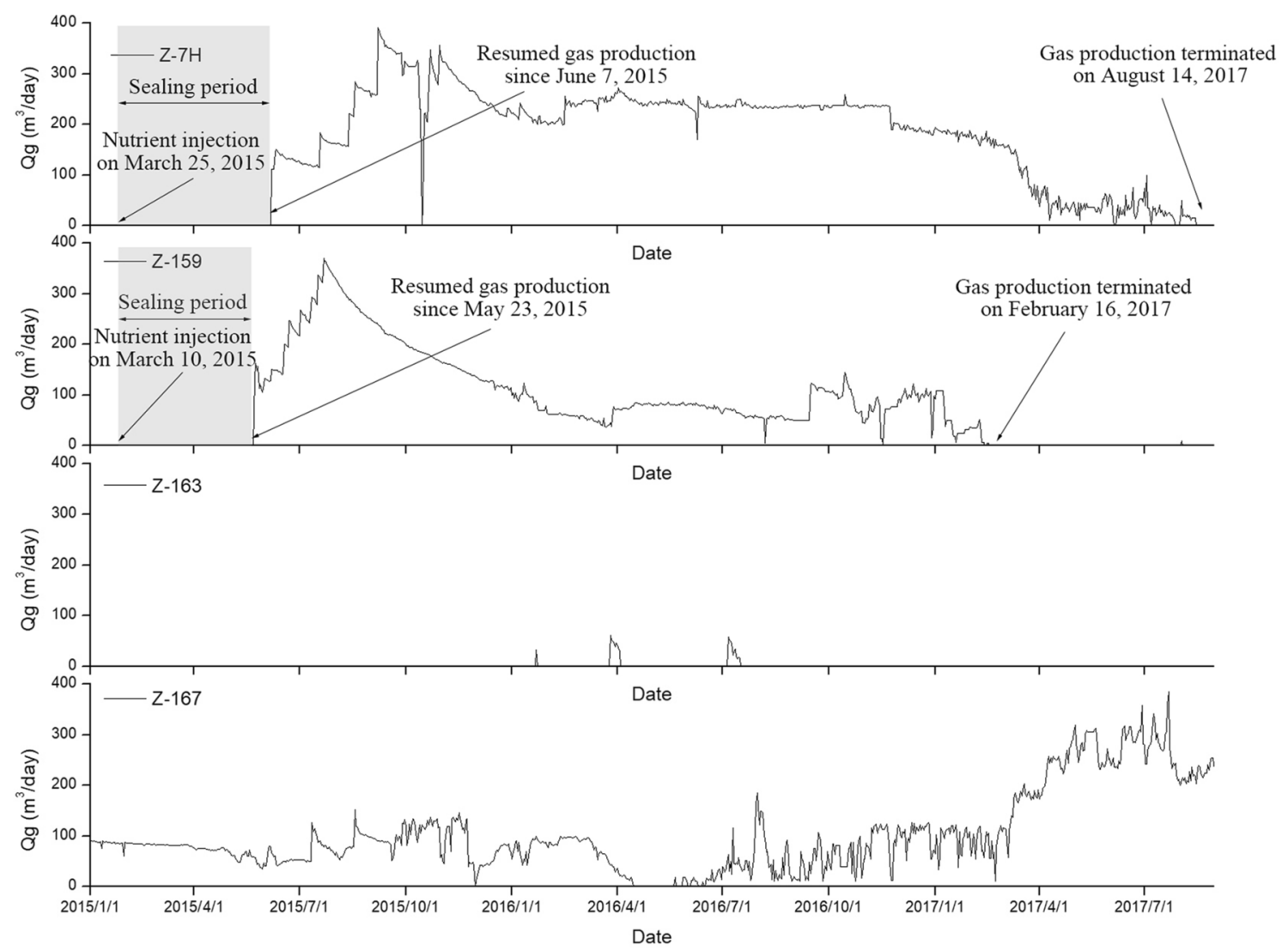

Fig. 4 Gas production (Qg) changes in experiment wells and in contrast wells during experiment. The $\mathrm{Z}-7 \mathrm{H}$ and $\mathrm{Z}-159$ were experiment wells. And Z-163 and Z-167 were contrast wells. The Z-159 well

Clostridiales. Anaerolinea has a fermentative metabolism, utilizing carbohydrates as well as proteinaceous carbon sources (Yamada et al. 2006). It produces acetate, lactate, and hydrogen as by-products of glucose fermentation (Sekiguchi et al. 2003). For Clostridiales, Peptococcaceae, and Clostridiales, they could produce butyric acid with organic fermentation. Varying concentrations of acetic acid, lactic acid and/or ethanol, propanol or butanol are also formed as fermentation products (Wiegel et al. 2006). They provided nutrients for methanogens and played important roles in the new biome. The relative abundance of these microbes was very low in original coal bed microbial community. The evolution of this coal bed ecological community demonstrates the critical role of this experimental method in improving the gas production capacity in situ.

\section{Summary and conclusions}

The experiment in this research was based on previous microbial gasification of anthracite in the laboratory. It was scheduled to verify the $\mathrm{CH}_{4}$ yield effect in coal seam through resumed gas production on May 23, 2015, and terminated on February 16,2017 . And the Z-7H wells resumed gas production on June 7 , 2015, and terminated on August 14, 2017

in situ experiment. The key factors in the experimental design include: (1) the nutrition was consistent with previous experiments; (2) it was necessary to clarify the relationship among the increase in CBM production, the diffusion of nutrition, the structure changes of coalbed microbial community. However, due to the on-site equipment conditions, weather, and road conditions, this research has some disadvantages such as the low sampling frequency of coalbed gas and liquid sample, the inability to measure the nutrient diffusion range in coal bed. The results of this experiment were as follows:

1) Results from this research have demonstrated that biogasification of coal could be utilized to enhance gas well productivity. The factor of $\mathrm{Cl}^{-}$concentration changes had been tested to assess the medium diffusion in coal. The significant difference in trace element indicates that the injection of culture medium significantly affects the nutrient structure of experimental wells (Z-159 and $\mathrm{Z}-7 \mathrm{H})$. The number changes of Methanoculleus spp. further confirmed this result. It is recommended to use $\mathrm{Br}^{-}$ion or biological tracing method instead of $\mathrm{Cl}^{-}$ion 
Fig. 5 Coalbed microbial community structures before and after experiment. SHR is microbial in row coal bed before experiment. And SHC is coal bed microbial after cultured

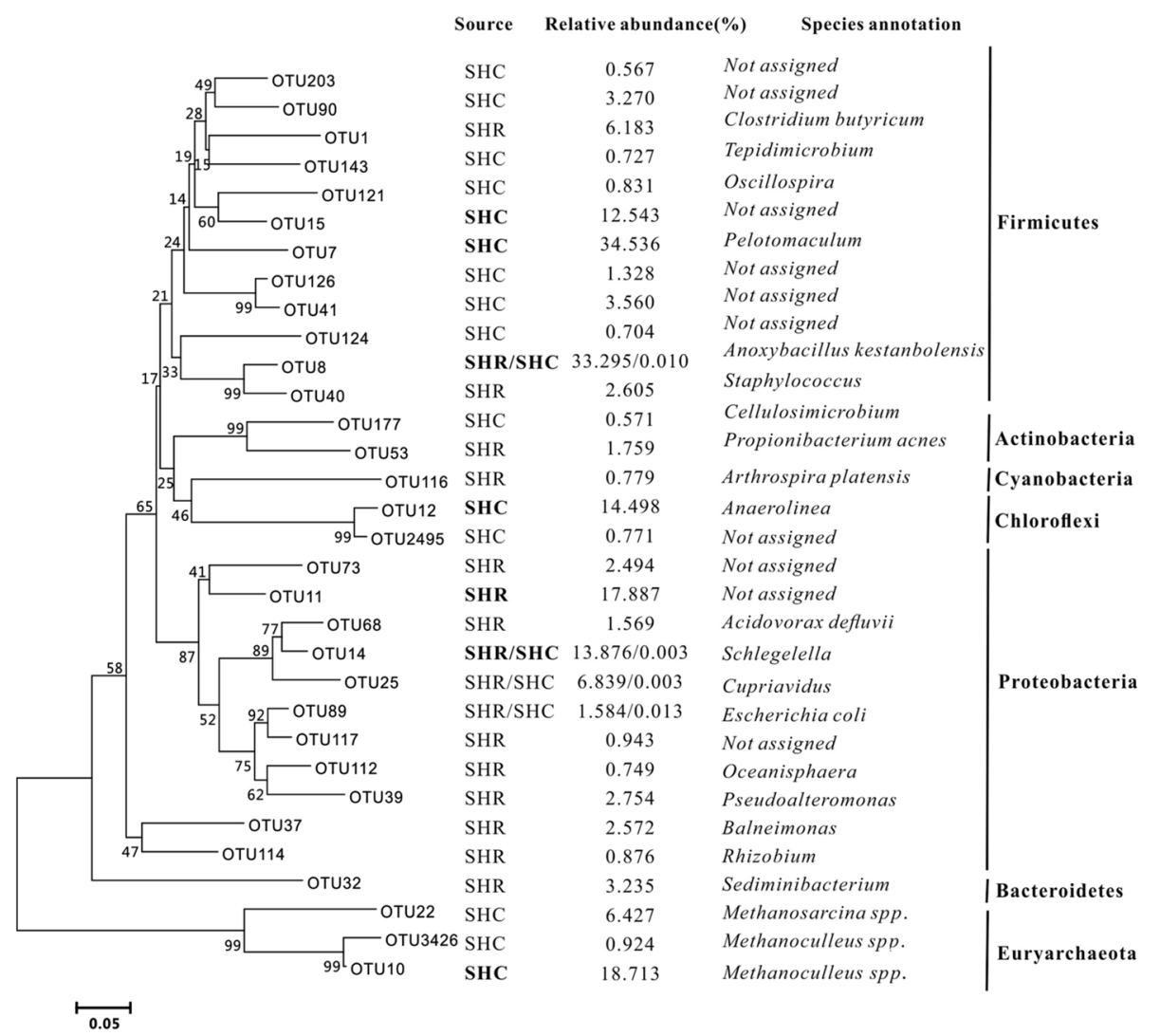

tracing in further experiments to improve the accuracy of tracing.

2) The difference in coalbed microbial diversity before and after the technology implementation, especially the evolution of dominant bacteria, which represented by Methanomicrobia spp., Anaerolineap, and Clostridialesp, confirms the feasibility of implementation of in situ coal bio-gasification. It is necessary to deeply explore the coupling relationship between gas production fluctuations and microbial community changes and reveal the mechanism of coal microbial utilization in further research.

3) CBM wells Z-7H and Z-159 realized the enhancement of gas production with varying degrees after medium injection. The increased rate and stability of gas production were related to the control range of CBM well. Gas composition analysis showed that the $\mathrm{CH}_{4}$ content in the $\mathrm{Z}-7 \mathrm{H}$ gas sample was $79.95 \%$ and in the $\mathrm{Z}-159$ gas sample was $87.00 \%$. Both were higher than laboratory experiments results. (The $\mathrm{CH}_{4}$ content in bio-gas was generally less than 62\%.) The high $\mathrm{CH}_{4}$ content may be caused by different gas adsorption characteristics of coal to $\mathrm{CH}_{4}$ and $\mathrm{CO}_{2}$. The specific reasons need further analysis.
This study initially confirmed the feasibility of the technology implementation of in situ bio-gasification for anthracite coal. However, how to use the culture medium more economically, build a recyclable coal microbial digestion network, and some key technologies such as coal microbial degradation rate control methods and environmental impact still need an in-depth study to lay a theoretical foundation for the industrialization of microbial gasification mining technology for coal resources.

Acknowledgements The authors' acknowledge the contributions of the following companies for allowing access to coal samples and other information used in this paper: Huabei Oil Field, Fenghuangshan mining, J\&D Technology Company. We thank Dr. Aikuan Wang and Jiang $\mathrm{He}$, China University of Mining and Technology, for instructions on data analyses. We thank Dr. Mohamed Keita for his contributions in the paper revision and language polishing. This work was supported by The Independent Research Project of State Key Laboratory of Coal Resources and Safe Mining, CUMT (grant number SKLCRSM22X005: DX), The Open Research Project of State Key Laboratory of Coal Resources and Safe Mining (grant number SKLCRSM17KFA08: DX), The Fundamental Key Projects of Shanxi Provincial Key Research and Development Program (grant number 201703D211003: YZ).

Author contributions DX, CZ and JW contributed to data curation; DX was involved in funding acquisition, Writing-original draft; $\mathrm{CZ}, \mathrm{EW}$, $\mathrm{HH}$ and $\mathrm{YZ}$ contributed to methodology; LD and MW were involved 
in project administration; NDD, EW contributed to writing-review and editing.

\section{Declarations}

Conflict of interest The authors declare that they have no conflict of interest.

Open Access This article is licensed under a Creative Commons Attribution 4.0 International License, which permits use, sharing, adaptation, distribution and reproduction in any medium or format, as long as you give appropriate credit to the original author(s) and the source, provide a link to the Creative Commons licence, and indicate if changes were made. The images or other third party material in this article are included in the article's Creative Commons licence, unless indicated otherwise in a credit line to the material. If material is not included in the article's Creative Commons licence and your intended use is not permitted by statutory regulation or exceeds the permitted use, you will need to obtain permission directly from the copyright holder. To view a copy of this licence, visit http://creativecommons.org/licenses/by/4.0/.

\section{References}

Allali I, Arnold JW, Roach J et al (2017) A comparison of sequencing platforms and bioinformatics pipelines for compositional analysis of the gut microbiome. BMC Microbiol. https://doi.org/10.1186/ s12866-017-1101-8

Asakawa S, Nagaoka K (2003) Methanoculleus bourgensis, methanoculleus olentangyi and methanoculleus oldenburgensis are subjective synonyms. Int J Syst Evol Microbiol. https://doi.org/10.1099/ ijs.0.02508-0

Barnhart EP, De León KB, Ramsay BD et al (2013) Investigation of coal-associated bacterial and archaeal populations from a diffusive microbial sampler (DMS). Int J Coal Geol. https://doi.org/ 10.1016/j.coal.2013.03.006

Chen M, Wu Y, Gao D, Chang M (2017) Identification of coal mine water-bursting source using multivariate statistical analysis and tracing test. Arab J Geosci. https://doi.org/10.1007/ s12517-016-2779-x

Fosso B, Santamaria M, Marzano M et al (2015) BioMaS: a modular pipeline for bioinformatic analysis of metagenomic amplicons. BMC Bioinform. https://doi.org/10.1186/s12859-015-0595-z

Galagan JE, Nusbaum C, Roy A et al (2002) The genome of M. acetivorans reveals extensive metabolic and physiological diversity. Genome Res. https://doi.org/10.1101/gr.223902

Green MS, Flanegan KC, Gilcrease PC (2008) Characterization of a methanogenic consortium enriched from a coalbed methane well in the Powder River Basin, USA. Int J Coal Geol. https://doi.org/ 10.1016/j.coal.2008.05.001

Grzegorzek M, Majewska-Nowak K, Ahmed AE (2020) Removal of fluoride from multicomponent water solutions with the use of monovalent selective ion-exchange membranes. Sci Total Environ. https://doi.org/10.1016/j.scitotenv.2020.137681

Guo H, Zhang Y, Zhang Y et al (2021) Feasibility study of enhanced biogenic coalbed methane production by super-critical $\mathrm{CO} 2$ extraction. Energy. https://doi.org/10.1016/j.energy.2020.118935

Hoang L, Phung TT, Urynowicz M et al (2021) First investigation of microbial diversity and biogenic methane potential in coal mines located in the Red River Basin Vietnam. Int J Coal Geol. https:// doi.org/10.1016/j.coal.2020.103674
Ji X, Song D, Ni X et al (2018) Coal matrix deformation and pore structure change in high-pressure nitrogen replacement of methane. Energies. https://doi.org/10.3390/en11010175

Kretschmann J (2020) Sustainable change of coal-mining regions. Min, Metall Explor. https://doi.org/10.1007/s42461-019-00151-2

Liang Y (2015) Theory and practice of integrated coal production and gas extraction. Int J Coal Sci Technol 2:3-11

Maeder DL, Anderson I, Brettin TS et al (2006) The Methanosarcina barkeri genome: comparative analysis with Methanosarcina acetivorans and Methanosarcina mazei reveals extensive rearrangement within methanosarcinal genomes. J Bacteriol. https://doi. org/10.1128/JB.00810-06

Malik AY, Ali MI, Jamal A et al (2020) Coal biomethanation potential of various ranks from Pakistan: a possible alternative energy source. J Clean Prod. https://doi.org/10.1016/j.jclepro.2020. 120177

McNeil NM, Alibali MW (2004) You'll see what you mean: students encode equations based on their knowledge of arithmetic. Cogn Sci. https://doi.org/10.1016/j.cogsci.2003.11.002

Mei J, He H, Hong FF et al (2021) Microbial community structures and sulfur speciation characteristics in soil sample around the Xiang-tan Liejiaqiao coal gangue dump, Hunan province in south of China. Energy Sources, Part a: Recovery, Util Environ Effects. https://doi.org/10.1080/15567036.2019.1648592

Neves ALA, Li F, Ghoshal B et al (2017) Enhancing the resolution of rumen microbial classification from metatranscriptomic data using kraken and mothur. Front Microbiol. https://doi.org/10. 3389/fmicb.2017.02445

Schloss PD, Jenior ML, Koumpouras CC et al (2016) Sequencing 16S rRNA gene fragments using the PacBio SMRT DNA sequencing system. PeerJ. https://doi.org/10.7717/peerj.1869

Sekiguchi Y, Yamada T, Hanada S, et al (2003) Anaerolinea thermophila gen. nov., sp. nov. and Caldilinea aerophila gen. nov., sp. nov., novel filamentous thermophiles that represent a previously uncultured lineage of the domain bacteria at the subphylum level. Int J Syst Evol Microbiol. https://doi.org/10.1099/ ijs.0.02699-0

Stra̧poć D, Picardal FW, Turich C et al (2008) Methane-producing microbial community in a coal bed of the illinois Basin. Appl Environ Microbiol 74:2424-2432. https://doi.org/10.1128/AEM. 02341-07

Szlązak N, Obracaj D, Swolkień J (2020) Enhancing Safety in the Polish High-Methane Coal Mines: an Overview. Mining, Metallurgy and Exploration 37

Wang Q, Garrity GM, Tiedje JM, Cole JR (2007) Naïve bayesian classifier for rapid assignment of rRNA sequences into the new bacterial taxonomy. Appl Environ Microbiol. https://doi.org/10.1128/ AEM.00062-07

Wang H, Cheng Y, Wang W, Xu R (2014) Research on comprehensive CBM extraction technology and its applications in China's coal mines. J Nat Gas Sci Eng. https://doi.org/10.1016/j.jngse.2014. 05.025

Wiegel J, Tanner R, Rainey FA (2006) An Introduction to the Family Clostridiaceae. In: The Prokaryotes

Xiao D, Peng SP, Wang BY, Yan XX (2013) Anthracite bio-degradation by methanogenic consortia in Qinshui basin. Int J Coal Geol 116-117:46-52. https://doi.org/10.1016/j.coal.2013.06.008

Xiao D, Peng SP, Wang EY (2015) Fermentation enhancement of methanogenic archaea consortia from an illinois basin coalbed via DOL emulsion nutrition. PLoS ONE 10:e0124386. https:// doi.org/10.1371/journal.pone.0124386

Xiao D, Wang E-Y, Peng S-P, Wu J-Y (2017) Responses of coal anaerobic fermentation fractures development. Meitan Xuebao/j China Coal Soci. https://doi.org/10.13225/j.cnki.jccs.2016.1109

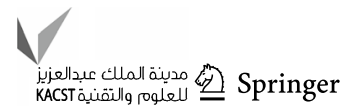


Xie XT, Kropinski AM, Tapscott B et al (2018) Prevalence of fecal viruses and bacteriophage in Canadian farmed mink (Neovison vison). MicrobiologyOpen. 8:e00622

Xu J, Zhai C, Qin L (2017) Mechanism and application of pulse hydraulic fracturing in improving drainage of coalbed methane. J Nat Gas Sci Eng. https://doi.org/10.1016/j.jngse.2017.02.012

Yamada T, Sekiguchi Y, Hanada S, et al (2006) Anaerolinea thermolimosa sp. nov., Levilinea saccharolytica gen. nov., sp. nov. and Leptolinea tardivitalis gen. nov., sp. nov., novel filamentous anaerobes, and description of the new classes anaerolineae classis nov. and caldilineae classis nov. in the . Int J Syst Evol Microbiol. https://doi.org/10.1099/ijs.0.64169-0

Yan X, Zhang S, Tang S et al (2021) A prediction model for pressure propagation and production boundary during coalbed methane development. Energy Fuels. https://doi.org/10.1021/acs.energ yfuels.0c03354

\section{Authors and Affiliations}

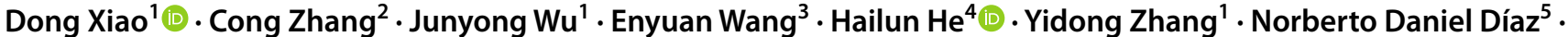 Liuping Deng ${ }^{2} \cdot$ Meng Wang ${ }^{4}$}

\author{
Cong Zhang \\ mcq_zhangc@petrochina.com.cn \\ Junyong $\mathrm{Wu}$ \\ wujy_90@126.com \\ Enyuan Wang \\ weytop@263.net \\ Yidong Zhang \\ ydzhangcumt@126.com \\ Norberto Daniel Díaz \\ ndanidiaz@gmail.com \\ Liuping Deng \\ yjy_dlp@petrochina.com.cn \\ Meng Wang \\ wangmengcugses@163.com
}

Zhang Z, Qin Y, Bai J et al (2018) Hydrogeochemistry characteristics of produced waters from CBM wells in southern Qinshui basin and implications for CBM commingled development. J Nat Gas Sci Eng. https://doi.org/10.1016/j.jngse.2018.06.024

Zhang A, Cao D, Wei Y, Rufford TE (2020) Characterization of fines produced during drainage of coalbed methane reservoirs in the linfen block. Ordos Basin Energy Explor Exploit. https://doi.org/ $10.1177 / 0144598720935528$

Publisher's Note Springer Nature remains neutral with regard to jurisdictional claims in published maps and institutional affiliations.
1 CUMT-UCASAL Joint Research Center for Biomining and Soil Ecological Restoration, State Key Laboratory of Coal Resources and Safe Mining, China University of Mining and Technology, Xuzhou 221116, Jiangsu province, China

2 Shanxi Coal Bed Methane Company of Petrochina, Jincheng 048000, Shanxi province, China

3 Key Laboratory of Gas and Fire Control for Coal Mines, China University of Mining and Technology, Xuzhou 221116, Jiangsu province, China

4 School of Life Science, Central South University, Changsha 410083, Hunan, China

5 CUMT-UCASAL Joint Research Center for Biomining and Soil Ecological Restoration, Universidad Católica de Salta, A4400EDD Salta, Argentina 